\title{
DESENVOLVIMENTO DE PRODUTOS VOLTADOS À PERCEPÇÃO TÁTIL DE CRIANÇAS COM DEFICIÊNCIA VISUAL
}

Lívia Solino (livia.solino@ifrn.edu.br) - CST em Design de Moda / Campus Caicó / IFRN (Instituto Federal de Educação, Ciência e Tecnologia do Rio Grande do Norte)

Roberta Fernandes (robertak2013@hotmail.com) - CST em Design de Moda / Campus Caicó / IFRN (Instituto Federal de Educação, Ciência e Tecnologia do Rio Grande do Norte)

Nataly Araújo Pinheiro (natalypinheiro1@outlook.com) - CST em Design de Moda / Campus

Caicó / IFRN (Instituto Federal de Educação, Ciência e Tecnologia do Rio Grande do Norte)

\section{RESUMO}

A moda não se trata apenas de apelo visual, ela pode proporcionar experiências sensoriais que ajudam a estimular outros sentidos como os táteis, adquiridos através do toque dos tecidos, olfativos como essências aplicadas nos produtos, e auditivos, empregando dispositivos sonoros em objetos, brinquedos, roupas e acessórios. O presente artigo busca discutir a implementação do sistema de cores Feelipa Color Code no vestuário infantil, contribuindo para o estimulo e percepção tátil de crianças com deficiência visual através do desenvolvimento de protótipos de t-shirts. A dimensão que o mercado de produtos de moda apresenta no Brasil é alta, mas o número de peças de vestuário inclusivos disponíveis ainda não é satisfatório, principalmente quando se trata do público infantil com deficiência visual. Para tais questões foi desenvolvida uma pesquisa aplicada, qualitativa e exploratória, onde os procedimentos técnicos utilizados serão de caráter bibliográfico e de pesquisa-ação, visto que houve a interação com os usuários da peça. Assim, propõe-se, de maneira lógica e estratégica, o planejamento e elaboração de uma ferramenta que inclua de fato e facilite a vida de crianças com deficiência visual, oferecendo informações e elementos que irão ajudar na sua independência e cotidiano.

Palavras chave: Moda inclusiva; Deficiência Visual; Sistema de Cores. 


\section{INTRODUÇÃ̃}

O Instituto Brasileiro de Geografia e Estatística (IBGE) apontou no censo de 2010 que havia no Brasil cerca de 45,6 milhões de pessoas com pelo menos algum tipo de deficiência (visual, auditiva, motora e mental), o que representa $23,9 \%$ da população, sendo a visual a mais frequente, atingindo 35,8 milhões. Para cada grupo de 100 crianças brasileiras de 0 a 14 anos de idade 7,5\% apresentam alguma deficiência, e entre elas 5,3\% é a visual. No Nordeste há no total 2.192.455 de crianças e adultos, cerca de 4,1\% da população local (IBGE, 2010).

A visão é um dos sentidos informacionais de dados necessários para a compreensão de determinados aspectos de itens de vestuário, é responsável por identificar a cor e o lado correto da peça, por isso pessoas com deficiência visual nem sempre podem se utilizar desse instrumento sensitivo normalmente usados para vestir, comprar, escolher, o que se torna uma tarefa complexas e difícil no seu cotidiano (BARBOSA \& ALBUQUERQUE, 2010).

A falta de produtos com tecnologias ou dispositivos acessíveis com informações customizadas ainda é limitado, o que reduz, em grande parte, a autonomia desse público com relação a interação com à moda e o vestuário, os tornando em grande parte dependentes da participação de terceiros para efetuar tarefas simples como escolher que roupa vestir (SCHNEIDER et al, 2017). Uma das dificuldades presentes na interação entre o deficiente visual e o vestuário diz respeito ao reconhecimento das cores, particularmente por aqueles que são cegos de nascença, pois encontram grandes dificuldades naturais com relação a compreensão de conceitos relacionados às cores (SENA, 2009).

A indústria da moda disponibiliza poucos dados manuais de instrução que contenham as explicações com relação a identificação das cores, a manutenção e conservação do produto para pessoas que não enxergam. A experiência tátil por meio do vestuário pode ajudar a incluir os deficientes na sociedade, pois informações necessárias presentes nos produtos através de métodos de apoio é de suma importância para inclusão social.

No mercado de moda infantil marcas vem desenvolvendo peças de vestuário lúdico, o que ajuda e traz a possibilidade de aprendizagem para as crianças, contribuindo para o desenvolvimento visual, tátil, olfativo e auditivo (PEREIRA; ANDRADE, 2013). Essa experiência tátil no vestuário pode incluir também as crianças com deficiência visual, os pais e a sociedade, que passam a ter conhecimento através da roupa da importância do papel da inclusão social. 
Diante do exposto, o presente artigo busca discutir, de forma fundamentada e numa perspectiva inclusiva, a implantação do sistema de cores Feelipa Color Code, a fim de contribuir para a percepção tátil e identificação das cores por crianças com deficiência visual, focando nas suas necessidades, oferecendo informações e elementos que irão ajudar na sua independência e cotidiano.

\section{FUNDAMENTAÇÃO TEÓRICA}

\subsection{Deficiência visual e a moda inclusiva}

A moda inclusiva procura abranger os vários tipos de corpos que geralmente a indústria não contempla, trata-se de um foco direcionado para mercados cada vez mais específicos, no qual são desenvolvidos projetos de criação de produtos para consumidores com algum tipo de deficiência ou mobilidade reduzida (AULER, 2014).

Pessoas com deficiência visual não apresentam alteração em sua estrutura física quando se trata de vestuário, porém, a percepção, assim como a identificação e autonomia no ato de vestir-se devem ser levados em consideração nos aspectos estéticos, práticos e perceptivos da roupa, principalmente quando se trata do vestuário infantil (BONONI, 2016).

A deficiência visual pode ser classificada como leve, moderada, severa ou profunda. Ela atinge um grupo de pessoas com visão subnormal ou pessoas com baixa visão, ou a ausência total da resposta visual. $\mathrm{O}$ indivíduo pode nascer com a deficiência (congênito) ou adquirir devido algum acidente ou doença, sendo esta parcial/temporária, reduzida ou irreversível (LIMA et al, 2013).

A pessoa que possui deficiência visual não "compensa" com seus outros sentidos devido à falta de visão, seus sentidos remanescentes são mais aguçados/desenvolvidos, porque eles recorrem a esses sentidos com mais frequência, tornando a escuta, tato e olfato mais treinado do que as pessoas que não tem deficiência visual (ULBRICHT et al, 2011).

O deficiente visual encontra muita dificuldade na hora de fazer compras, pois fazer o reconhecimento de peças, combinar as cores, modelos e identificar as informações dos produtos são tarefas difíceis de serem praticadas quando não é disponibilizado alguma experiência tátil ou auditiva sobre tamanho, cor ou tipo de tecido para facilitar tanto na escolha quanto no uso do produto (OLIVEIRA, et al, 2017, p. 11). 
Uma das formas de comunicação que pode ser inserido no vestuário e pode facilitar na hora da compra é o braille. Ele foi inventado por Louis Braille em 1825, é um sistema de leitura e escrita tátil para cegos, ou seja, a leitura com as mãos que era usado com base em um código militar com o objetivo de facilitar a comunicação noturna. É composto por 64 símbolos por meio de seis pontos posicionados em variadas posições ao longo de três colunas, além de possuir 63 sinais (CANEJO, 2005).

A etiqueta em braille no vestuário ajuda na identificação, através do tato, dos tamanhos, cores, tipos de tecido entre outros aspectos que podem ajudar a remover barreiras de comunicação. O tato é responsável por variadas sensações tais como calor, frio, pressão e dor que são captadas por receptores existentes na epiderme (SENA, 2009). Já com relação as crianças que nascem cegas ou perdem a visão na primeira fase da infância, o braille é indispensável, pois ajuda e contribui para as necessidades diárias das crianças, na identificação de objetos e tarefas do dia a dia, tornando-os mais independentes, o seu uso frequente irá ajudar a terem um nível mais alto de educação e melhores oportunidades na fase adulta, e é um dos métodos de ensino e leitura bastante consistente.

\subsection{Deficiência visual e a relação com as cores na moda}

Na moda, uma das primeiras exigências e escolha na hora da compra pelo consumidor é a cor, por isso, no momento da criação de uma coleção, uma das decisões a serem tomadas pelo designer é com relação a cartela de cores, sendo essa escolha determinada por fatores como tendência, clima e estação (SENA, 2009 apud, JONES, 2005).

Segundo Farina (2006), a cor é um elemento que pode interferir no humor de cada indivíduo de forma diferente, sua escolha pode estar associada às experiências, desejos e afinidades. A cor é uma característica da moda e está intimamente ligada aos estilos de vida e grupos da sociedade, o que comprova, por exemplo, a preferência por tons escuros em épocas de crise, protestos ou luto (TURATTI, 2011).

A cor é bastante utilizada na nossa linguagem, ela ajuda a revelar e identificar de instrumentos, mapas, gráficos e outros elementos visuais. Para o deficiente visual a cor é um aspecto de comunicação extremamente importante, porém, nos produtos atualmente desenvolvidos ainda não há técnicas utilizadas frequentemente, como o código em braille, que ajude a facilitar o reconhecimento das cores para um deficiente visual, necessidade que se torna importante como forma de inclusão (ANCZUROWSKI, 1987 apud, OLIVEIRA et al, 2017). 
O daltonismo ${ }^{1}$, que afeta a percepção correta das cores e causa confusão das mesmas, é uma anomalia congênita e ocorre pela ausência ou insuficiência de cones na retina que são responsáveis pela percepção das cores (Neiva, 2008). Segundo o IBGE (2010), no Brasil existem cerca de 6,2 milhões de pessoas com deficiência visual o que afeta $10 \%$ da população mundial onde $98 \%$ dos afetados são do sexo masculino. Os portadores têm sua visualização prejudicada e apresentam dificuldades em identificar as cores primárias, o que prejudica a visualização do restante do espectro luminoso (QUADROS apud, FERREIRA, 2012).

O daltonismo é também conhecido como "cegueira das cores", anomalia que dificulta algumas atividades diárias, inclusive com relação a moda, onde algumas cores visualizadas não têm relação alguma com a cor real dos produtos, o que pode trazer com algum constrangimento por falta de identificação correta das cores das roupas, no vestir-se e nas compras (QUADROS et al, 2017).

$\mathrm{Na}$ tentativa de buscar melhorar a qualidade de vida de pessoas que convivem com deficiências visuais e permitir que elas percebam as cores através de formas geométricas, a designer portuguesa Filipa Nogueira Pires criou um sistema de cores com nome de Feelipa Color Code em 2009. A ideia é transformar o código universal, assim como a escrita em braile, permitindo o seu uso em diversos objetos do dia-a-dia, como roupa, medicamentos, tendo como objetivo tornar a cor acessível ao maior número de pessoas possível, em particular às pessoas com algum tipo de deficiência visual.

O código de cores foi desenvolvido para auxiliar os deficientes visuais por meio da associação simples de formas geométricas universais, apresentadas em alto relevo, que podem ser aplicadas em vários tipos de materiais, inclusive os tecidos, onde suas principais características são a memorização fácil e o reconhecimento sem esforço das formas, permitindo melhor reconhecimento tátil, aumentando com isso a autonomia das pessoas com deficiência visual (OLIVEIRA et al, 2017).

\footnotetext{
${ }^{1} \mathrm{O}$ daltonismo é um tipo de deficiência visual que interfere na percepção das cores. Também chamado de discromatopsia ou discromopsia tem como principal característica deste distúrbio, a dificuldade de reconhecimento e diferenciação de cores primárias, como o vermelho e o verde e, em outros casos, o azul e o amarelo. Há também casos de visão acromática, em que só são vistos os tons de branco, cinza e preto. Essa deficiência ocorre devido a um problema com os pigmentos de algumas cores nos cones, células nervosas do olho. Dependendo do grau, o daltonismo pode limitar ou impedir o exercício de atividades cotidianas das pessoas, condição que a define como pessoa com deficiência, segundo o decreto $n^{\circ} 3.956 / 01$ (BRASIL, 2001).
} 
O funcionamento do código é bem simples, onde as formas geométricas quadrado, triângulo e círculo são associados às cores primárias vermelho, amarelo e azul. Já com relação as cores secundárias como verde, laranja e roxo, estas são inseridas nas novas formas geométricas, que unidas as formas primárias dão base há uma nova formação. E as cores preto, cinza e branco são representadas por linhas com espessura suficiente para o reconhecimento tátil, fazendo do código um sistema simples, lógico e intuitivo (OLIVEIRA et al, 2017).

Figura 01 - Código criado por Filipa Nogueira Pires

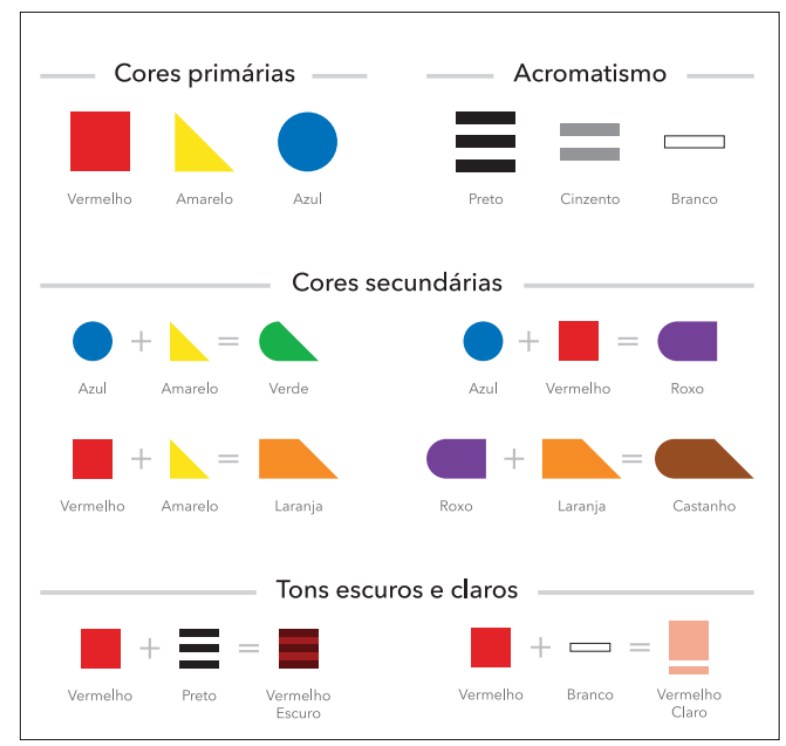

Fonte: http://www.feelipa.com/pt/para-deficientes-visuais/

\section{METODOLOGIA}

Quanto à natureza da pesquisa, esta se classifica como aplicada, uma vez que teve como motivação a necessidade de produzir conhecimento para aplicação de seus resultados, com o objetivo de contribuir para fins práticos, visando à solução do problema encontrado na realidade, envolvendo verdades e interesses locais (BARROS E LEHFELD, 2000). A abordagem do problema, é considerada como uma pesquisa qualitativa devido à preocupação em analisar e interpretar aspectos mais aprofundados, visando avaliar a eficiência do produto junto a criança, observando a experiência vivida pelo usuário e a sua evolução quanto ao conhecimento e interpretação das cores e a sensibilidade tátil (MINAYO, 2011).

A metodologia utilizada é de caráter exploratório por ter o objetivo de formular questões ou problemas com triplas finalidades, entre elas o convívio dos pesquisadores com a família e 
a criança, obtendo mais proximidade com os problemas que poderão ocorrer no decorrer do desenvolvimento do produto, sendo possível elaborar soluções e alternativas (LAKATOS; MARCONI, 2010).

Quanto aos procedimentos técnicos utilizados, a pesquisa iniciou com a pesquisa bibliográfica, feita a partir de materiais já elaborados, que serviu de embasamento para o desenvolvimento das $t$-shirts (GIL, 2009). Ao passo que as $t$-shirts foram produzidas e testadas, o procedimento técnico utilizado foi de uma pesquisa-ação, realizada em associação com a resolução de um problema coletivo, onde os pesquisadores e participantes da situação investigada estiveram envolvidos de modo cooperativo (THIOLLENT, 2009).

Para que o objetivo da pesquisa fosse alcançado, 4 etapas foram adaptadas das metodologias projetuais de Löbach (2001) e Baxter (2011). Inicialmente foi feita uma fundamentação teórica, analisando a moda inclusiva, a deficiência visual e a relação dos mesmo com as cores na moda, obtendo uma maior familiaridade com o tema pesquisado. A segunda etapa abrangeu a elaboração e construção do protótipo, na terceira foram feitos testes de usabilidade com uma criança com deficiência visual e por fim, foi feito uma avaliação do produto e análise dos resultados alcançados. Dessa forma, a intenção da pesquisa é apresentar uma contribuição do sistema de cores no vestuário para crianças com deficiência visual.

\section{RESULTADOS E DISCUSSÕES}

A principal preocupação durante a elaboração e construção do protótipo foi a de confeccionar peças com características funcionais e ergonômicas, que proporcionem liberdade de movimento, conforto e bem-estar ao usuário. Foram confeccionadas algumas $t$-shirts com formas geométricas e cores primarias utilizando o sistema de cores Feelipa Color Code.

No processo de construção dos protótipos, as dificuldades e descobertas que aconteceram foram em relação ao tamanho tanto da peça como também dos objetos, pois foi possível constatar que para construir vestuário, acessórios ou qualquer outro item infantil requer muita paciência, delicadeza e cuidado, sendo um trabalho meticuloso e, por serem de tamanho pequeno, tornam o trabalho mais lento.

Para o desenvolvimento foram feitas as modelagens, cortes e na sequência as pinturas e aplicações das estampas. Os matérias utilizados foram: malha 100\% CO, feltro 100\% PES, linhas, velcro, tesoura e tinta. Após a modelagem a peça foi cortada, antes de fechar foi colocado 
o bolso, e em seguida foi riscado e aplicado o contorno da estampa com a tinta puff, para dá o efeito 3D, finalizando com a costura.

$\mathrm{Na}$ elaboração e construção dos protótipos foram confeccionadas algumas $t$-shirts (Figura 02) que possuem a mesma funcionalidade, porém estéticas diferentes, uma foi desenvolvida com formas geométricas e cores, direcionada as crianças com idade entre 3 e 5 anos, outra com lápis, formas geométricas e cores para crianças com idades entre 6 e 9 anos. Apesar das duas peças terem sido confeccionadas, no momento da pesquisa só foi possível realizar o teste de usabilidade com uma criança de 9 anos, sendo testada a peça que contém os lápis, formas geométricas e cores primarias, conforme está exposto na Figura 02.

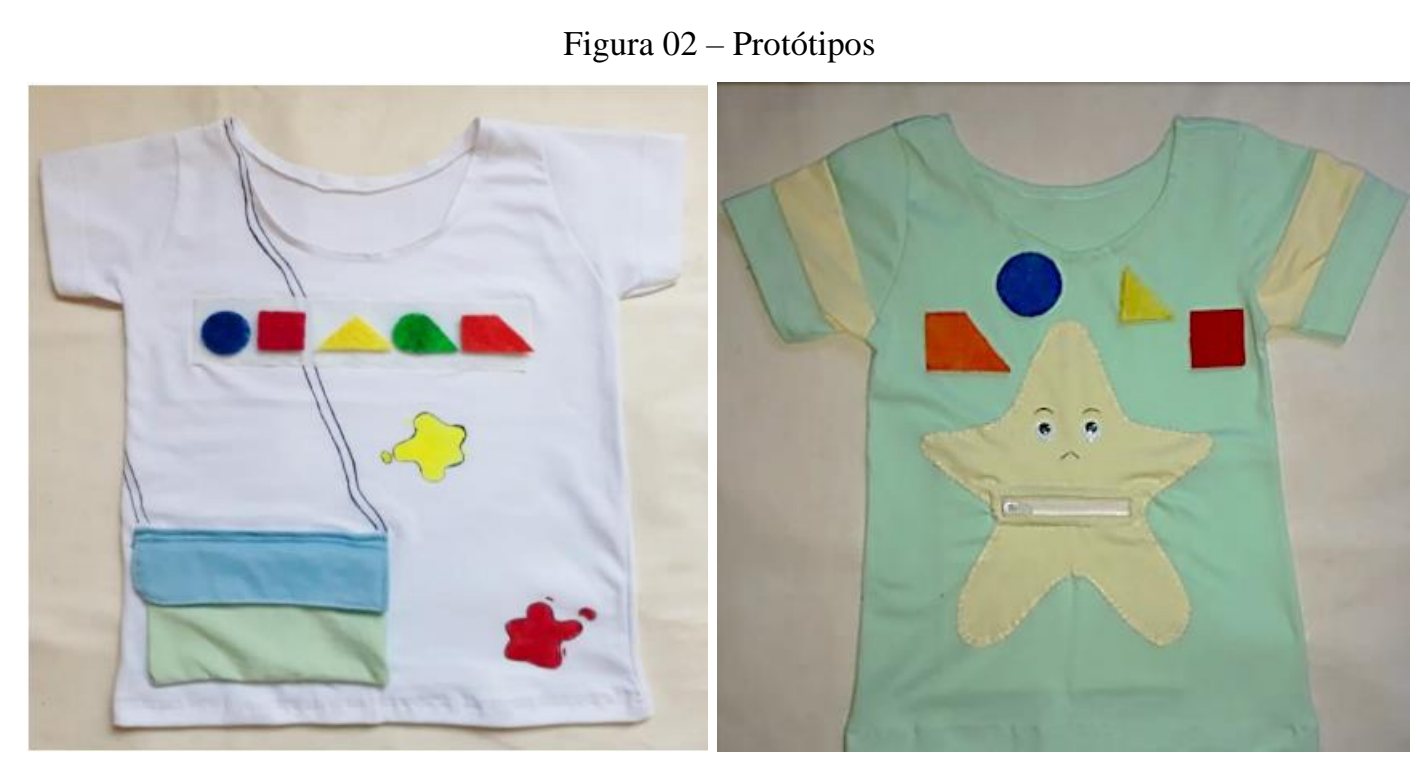

Fonte: Elaborados pelos autores (2018).

A fim de confirmar a eficácia da $t$-shirt foram realizados testes de usabilidade e os conceitos de interatividade e desenvolvimento infantil foram aplicados com a utilização do bolso, onde os lápis e objetos podem ser guardados. O design busca auxiliar no desenvolvimento da percepção e interpretação por meio da exploração sensorial, além de buscar contribuir nos movimentos, despertando a curiosidade da criança, e desenvolvendo melhor a sua sensibilidade tátil. Já os lápis foram decorados com as formas geométricas associadas as cores primarias como sugere o código, tornando a identificação simples, interativa, dinâmica e fácil de memorizar.

Para a realização do teste de usabilidade do produto todos os envolvidos foram convidados a participarem da pesquisa como voluntários, e preencheram o Termo de 
Consentimento Livre Esclarecido (TCLE) autorizando a divulgação dos resultados dos testes e dos registros fotográficos em publicações de cunho científico.

No teste realizado foi possível observar a independência e autonomia da participante na realização das atividades interativas proposta pela peça. A utilização de texturas táteis e o uso das cores vinculados aos lápis foram artifícios considerados satisfatórios e aceitos pela criança. A prática e o uso continuo da peça poderá ser um recurso auxiliador na construção e inclusão da criança na sociedade, contribuindo para o desenvolvimento da percepção e interpretação das cores, facilitando o cotidiano escolar, uma vez que a criança poderá colorir desenhos e escolher os tons propostos pela professora ou os que desejar para as suas atividades escolares.

A percepção tátil com relação ao código de cores Feelipa foi confirmada no teste, a identificação das formas geométricas assimilando-as as cores primarias foi bem memorizada pela criança, além do ato interativo de abrir, e direcionar os lápis para o quadro de feltro na $t$ shirt foram atividades dinâmicas e de fácil manuseio.

Figuras 03 - Teste de usabilidade com a criança de 8 anos.

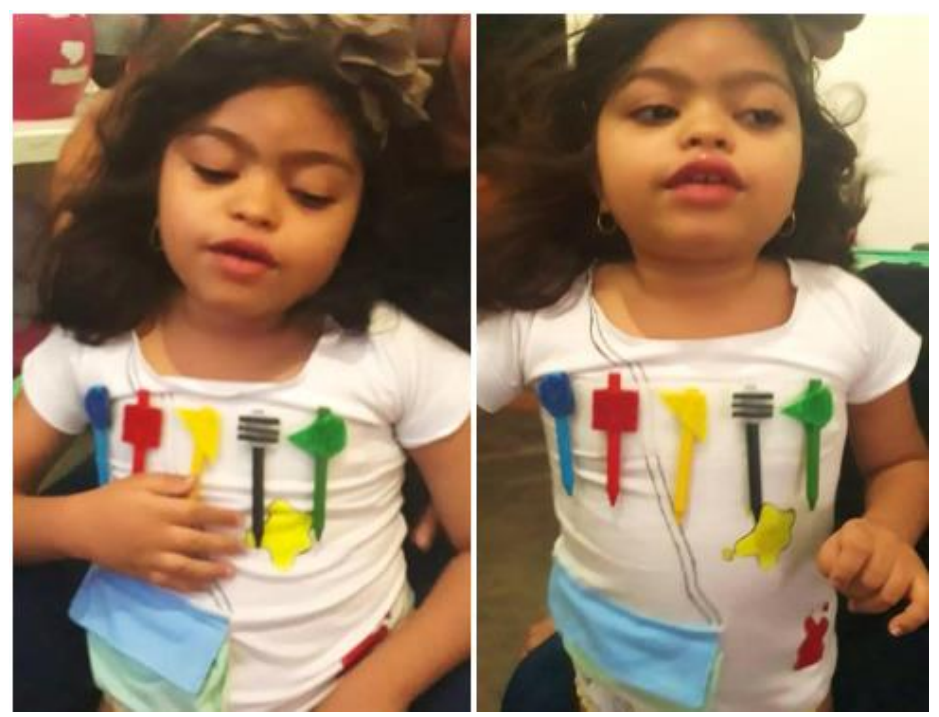

Fonte: Elaborados pelos autores (2018).

Um ponto fundamental que não se pode deixar de destacar foi a importância da participação da família, seu envolvimento, conhecimento, habilidade com a criança, e acima de tudo, a vontade de proporcionar mais oportunidades de conhecimento, autonomia, liberdade e inclusão ajudaram nos testes. 


\section{CONSIDERAÇÕES FINAIS}

O propósito do artigo foi contribuir para a discussão sobre moda inclusiva ao apresentar relatos sobre a relação dos usuários com o produto proposto. A intenção é gerar discussões a respeito do assunto, contribuindo não apenas para o meio acadêmico, mas também na vida social dos envolvidos e crianças com deficiência visual.

Através da utilização do sistema de cores Feelipa Color Code no vestuário foi possível a interação da criança com a roupa, ajudando-a a conhecer e identificar não só as cores mas também as formas geométricas, focando nas suas necessidades, o que pensam e sentem, oferecendo informações e elementos que possam contribuir para sua independência e cotidiano.

Ao desenvolver e testar protótipos, foi possível identificar aspectos referentes às necessidades do público infantil, no que concerne às dificuldades sobre o uso das roupas, como imaginam e vê os objetos e o mundo ao seu redor. Como resultado espera-se que proposta desenvolvida atenda às necessidades dos usuários com o menor custo possível e que a ideia possa ser amplamente reproduzida.

A construção dos protótipos, estampas, e formas geométricas, foram realizados de forma artesanal, porém podem ser feitas em larga escala e industrialmente, caso a proposta seja patenteada. Com o teste de usabilidade foi possível verificar a eficiência com relação a identificação das cores e formas, atendendo as necessidades das crianças por meio do vestuário, fazendo com que a $t$-shirt seja útil e atrativa, e que a criança se sinta motivada a utilizá-la.

Interagir com a peça permite que a criança aprenda de forma divertida e produtiva, desenvolvendo assim suas potencialidades, preparando-as para a vida adulta. A utilização de brincadeiras por meio do vestuário com crianças cegas e de baixa visão é um veículo para o desenvolvimento das suas capacidades (BONONI et al. 2016).

Espera-se que a proposta de vestuário que forneça experiências táteis para crianças com deficiência possa contribuir para a discussão sobre moda inclusiva através dos relatos apresentados sobre a relação da participante com a peça desenvolvida.

\section{REFERÊECIAS}

ANCZUROWSKI, E., inventor. Representation of Color for Blind Persons. US patente US 4650421. 1987 May. 17. Disponível em:

<https://patentimages.storage.googleapis.com/pdfs/e87b466cb039c01cb7e7/US4650421.pdf>. Acesso em: 05 de maio de 2019. 
AULER, D. Moda inclusiva: perguntas e respostas para entender o tema. Governo do Estado de São Paulo, Secretaria de Estado dos Direitos da Pessoa com Deficiência, 2012.

Disponível:http://www.pessoacomdeficiencia.sp.gov.br/usr/share/documents/MODA_INCLUSIVA_DIGITAL_ CARTILHA_FINAL.pdf acessado em 12/05/2019.

BARBOSA, M. B.; ALBUQUERQUE, R. de M. A. Comunicação, Sinalização e Acessibilidade. In: PRADO, A. R. de A.; LOPES, M. E.; ORNSTEIN, S. W. (Org.). Desenho universal: caminhos da acessibilidade no Brasil. São Paulo: Annablume, 2010.

BARROS, A. J. S. e LEHFELD, N. A. S. Fundamentos de Metodologia: Um Guia para a Iniciação Científica. 2 Ed. São Paulo: Makron Books, 2000.

BONONI, J. Design do vestuário infantil: As texturas como experiência tátil para crianças deficientes visuais. Pós-graduação em Design UNESP, 2016. Disponível em: https://repositorio.unesp.br/bitstream/handle/11449/138569/bononi_j_me_bauru.pdf;jsessionid=BF3703EEC0846C476D5D59EA9EFAD91A?sequence $=3$ acessado em: 05/05/2019.

CANEJO, Elizabeth. Apostila introdução ao sistema Braille. Fundação de Apoio à Escola Técnica - FAETEC. Diretoria do Desenvolvimento da Educação - Gerência de Programa de Inclusão. Governo do Estado do Rio de Janeiro, 2005.

FARINA, Modesto. Psicodinâmica das cores em comunicação. 5a Edição. São Paulo, SP: Edgard Blücher, 2006.

FERREIRA, L. M. do R. Análise do processamento de sinal visual através de eletroencefalograma em indivíduos daltónicos comparativamente com indivíduos normais. Covilhã, 2012, p. 93. Dissertação (mestrado em Engenharia Eletrotécnica e de Computadores Ramo Sistemas Biónicos) - Departamento de Ciência e Tecnologia Têxteis. Universidade da Beira Interior, 2012.

GIL, A. C. Estudo de caso. Atlas, 2009.

IBGE -INSTITUTO BRASILEIRO DE GEOGRAFIA E ESTATÍS-TICA. Censo Demográfico 2010: Características gerais da população, religião e pessoas com deficiência. São Paulo: IBGE, 2010. 215p.

LAKATOS, E. M.; MARCONI, M. A. Metodologia científica. São Paulo: Atlas, 2000. _. Metodologia do trabalho científico, v. 6, 2010.

LIMA, A.C.E.; FERREIRA, J.C.; SILVA, R.G. da. Deficiência Visual: vida independente e inclusão. 2013. Disponível em http://www.faeterj-caxias.net/revista/index.php/edutec/article/view/42 Acessado 20/05/2019.

NEIVA, M. Sistema de Identificação da Cor para Daltônicos: Código Monocromático. Dissertação de Mestrado. Universidade do Minho, Portugal, 2008.

OLIVEIRA, Tainá Apoena Bueno de; CINELLI, Milton José. Sistemas de Cores Táteis: Estudo Comparativo de suas Vantagens e Limitações para Pessoas com Deficiência. Congresso Internacional de Ergonomia e Usabilidade de Interfaces Humano Tecnológica, 2017, Santa Catarina. Disponível em: https://www.researchgate.net/publication/319364796_SISTEMAS_DE_CORES_TATEIS_estudo_comparativo_ de_suas_vantagens_e_limitacoes_para_pessoas_com_deficiencia acessado em 06/04/2018.

PEREIRA, Lívia Marsari; ANDRADE, Raquel Rabelo. Vestuário infantil com conceitos de aprendizagem. Disponível em: www.uel.br/revistas/uel/index.php/projetica/article/viewFile/ Acesso em: 02 de outubro 2018.

QUADROS, R. C.; SCOPEL, C.;VIEIRA, F. D.. Daltovest aplicado para moda inclusiva: a percepção de pessoas daltônicas em relação aos produtos de vestuário. 2017. Trabalho de Conclusão de Curso (Graduação em Design de Moda) - Universidade Comunitária da Região de Chapecó. Disponível em:

https://modainclusiva.sedpcd.sp.gov.br/wpcontent/uploads/2018/12/ModaInclusiva2018_miolo.pdf acessado em $12 / 05 / 2019$

SCHNEIDER, J.; FERREIRA, M. G. G.; RAMIREZ, A. R. G.; SANTOS, C. T. Etiquetas têxteis em braille: uma tecnologia assistiva a serviço da interação dos deficientes visuais com a moda e o vestuário. ESTUDOS EM DESIGN (ONLINE), v. 1, p. 65-85, 2017.

SENA, M. D. C. Etiqueta Têxtil como Contributo para a Interpretação da Cor pelos Deficientes Visuais. Dissertação (Mestrado em Design de Moda/Vestuário) — Covilhã, Universidade da Beira Interior, 2009. 
Disponível em: https://ubibliorum.ubi.pt/bitstream/10400.6/1259/1/DISSERTACAO_final2.pdf Acesso em: 02 de maio 2019.

TURATTI, J. B. O preto e o branco na moda. 2011. Trabalho de Conclusão de Curso (Graduação em Design de Moda e Tecnologia) - Universidade Feevale. Disponível em: https://docplayer.com.br/7404804-Cor-ecomunicacao-o-preto-e-branco-na-moda.html acessado em 12/05/2019.

ULBRICHT, V.R. Et al. Os Deficientes visuais e a aprendizagem da representação espacial. Gráfica 2011. 